\title{
Assessment Mixing and Compaction Temperatures for Modified HMA Using Superpave High Shear Viscosity Methods
}

\author{
Alaa Hussein Abed \\ Ali Hwaidi Nasser \\ Civil Eng. Dep., Al-Nahrain University, Baghdad, IRAQ \\ Alaa.abed@eng.nahrainuniv.edu.iq ali6719900@gmail.com \\ Received: 12-June-2018 Revised: 22-Oct.-2018 Accepted: 14-Nov.-2018 \\ http://doi.org/10.29194/NJES.21040516
}

\begin{abstract}
The objective of this study is determining the mixing and compaction temperature of the modified asphalt mixture. Results of binder tests showed that the addition of $3 \%$ SBS to control asphalt (PG 64-16) would achieve the desired performance level (PG 76-16) a performance grade that fits our climate with traffic loads. When using $5 \%$ SBS the performance grade of binder increased three grades (PG 82-16) and when increasing SBS content to $8 \%$ the performance grade increased four grades (PG 88-16). At shear rate of 500 (s-1), the modified asphalt viscosity can be obtained at different temperatures and the viscosity temperature curve can be achieved. As a result, the mixing and compaction temperature of modified asphalt can be determined to reach $0.17 \pm 0.02 \mathrm{~Pa}$.s and $0.28 \pm 0.03 \mathrm{~Pa} . \mathrm{s}$ for mixing and compaction, respectively. It is noted that SBS modified reached a viscosity of 3 Pa.s when $8 \%$ additive. Additive contents above these values may not be suitable for good workability and pump ability according to Superpave specifications. While addition of $5 \%$ SBS with control asphalt, more than 3.7times at $135^{\circ} \mathrm{C}$ Increase the viscosity. Marshall Stability test indicated that the strength for the SBS specimens increases as compared to the conventional specimens. An increase of about $39 \%, 74 \%$, $102 \%$, was observed with $3 \%$ SBS 5\% SBS $8 \%$ SBS modified binders, respectively. The Marshall test results for $8 \%$ SBS binders required compaction temperatures above $175^{\circ} \mathrm{C}$ need to keep up quality of HMA item while limiting natural effect amid development, these proposals are unsatisfactory Modified mixtures the $5 \%$ SBS modification was determined to be the maximum useful content. The Superpave method to estimate mixing and compaction temperatures show are not practical for use with modified binders. Also, it is observed that good agreement values between the average Marshall compaction temperature and the High Shear Viscosity Method (HSRV) and lower than Superpave methods Where the decline ranges from $15^{\circ} \mathrm{C}$ to $17^{\circ} \mathrm{C}$.
\end{abstract}

Keywords: SBS, HMA Mixing And Compaction Temperatures, HSRV, Modified Asphalt Mixture.

\section{Introduction}

The challenges associated with heavily repeated axle loads and weather factors in Iraq have been the subject of research for many years to improve asphalt pavement resistance [2]. Asphalt binder is cementations material that is considering a non-volatile at ambient temperatures and softens as heated. Asphalts are often refused as viscoelastic materials elastic solid at low temperatures and viscous at high temperature. Compaction is a process of condensation in which the air is expelled from the blanks of the hot mix. This is done using mechanical means, resulting in a decrease in the volume of the air voids and an increase in the density of the hot asphalt mixture Viscosity is checked to ensure that the asphalt is sufficiently liquid to cover aggregates. If the viscosity is high, the viscosity should be reduced by heating the asphalt to obtain the required flow to enable the mixing process. Several binder asphalt rates are the same as heat, delicate and may damage through incorrect use. Lastly, one must reflect the costs of Production, which may be increased by the excessive use of energy and the necessary precautions to protect workers and neighboring populations. It makes sense to achieve that around is a perfect temperature variety for binder manufacture. Significantly, mixing and compaction temperatures for asphalt must not surpass anything are required to realize the bulk density that meets the requirements. Modified asphalt binder remains in non-Newtonian fluids even at high temperatures. Asphalt binder modified viscosity increases rapidly with a lower shear rate to pretend the condition of the viscosity asphalt binder in the procedure of bleeding and compaction temperature of hot max asphalt. Thus, viscosity of asphalt binder below high shear rate can be extrapolated through the establishment of a relationship between shear rate and viscosity [9]. Shear rate of $490 \mathrm{~S}-1$ is suggested based on the corresponding viscosity versus the shear rate relationship of modified [11]. The determined temperatures, obtained with a procedure that involve viscosity measurements extrapolation out of high temperature condition, matched well with the temperature ranges used in practice. of arrival. Adaptive array not only directs the maximum radiation in the direction of desired signal but also introduces 


\section{Material Used In The Work}

The material used in this research has been tested according to the ASTM standard and compared to the results achieved by the Iraqi Standard Specification [8].

\subsection{Aggregates}

AL-Nebai aggregate was the use of in this research: an angular, relatively porous crushed limestone, rounded, smooth, and natural sand. The aggregate was sieved and re-aggregation was performed to meet the requirements of wearing course gradation according to the SCRB (R/9, 2003) specification, showing the physical properties of aggregates in Table (2).

\subsection{Filler}

Aggregate passing through $0.075 \mathrm{~mm}$ IS sieve is called as filler. Here Limestone Dust produced in the Karbala lime Factory is used as filler. Table (1) shows the physical properties of Limestone Filler.

Table (1): properties of Limestone Filler

\begin{tabular}{|l|c|}
\hline \multicolumn{2}{|c|}{ Property } \\
\hline Passing Sieve No 200 , \% & $95 \%$ \\
\hline
\end{tabular}

\begin{tabular}{|l|c|}
\hline Apparent Specific gravity & 2.623 \\
\hline Surface Area $\left(\mathbf{m}^{\mathbf{2}} / \mathbf{k g}\right)$ & 395 \\
\hline
\end{tabular}

\section{Asphalt binders}

Asphalt with penetration grade (40/50) from Nasiriyah refineries, Iraq. It use throughout the entire study as a control binder that specific gravity was (1.04) and to prepare the polymer-modified binder for preparation of mix. The physical properties of the control asphalt binder are outline in Table (3)

\subsection{Styrene-Butadiene-Styrene (SBS) Modified}

Poly(styrene-butadiene-styrene), or SBS called a block copolymer, made by styrene and butadiene connected homopolymer pieces, of thermoplastic elastomers are widely used around the construction of major roads in the world. The structure of a Styrene Butadiene Styrene copolymer therefore contains of SBS tripartite block chains, the presence of the morphological stage of polystyrene block domains spherical within the matrix of poly butadiene [1].

Table (2): Properties of Aggregate

\begin{tabular}{|c|c|c|c|c|c|}
\hline \multicolumn{2}{|c|}{ Laboratory Test } & $\begin{array}{l}\text { Designation and } \\
\text { Snecification }\end{array}$ & \multicolumn{3}{|c|}{ Results } \\
\hline \multirow{3}{*}{ Specific gravity } & \multirow{2}{*}{$\begin{array}{c}\text { Coarse } \\
\text { aggregate }\end{array}$} & \multirow[t]{2}{*}{ ASTM (C-127) } & $\begin{array}{c}\text { apparent specific } \\
\text { gravity }\end{array}$ & $\begin{array}{c}\text { Bulk specific } \\
\text { gravity }\end{array}$ & $\begin{array}{c}\text { Water } \\
\text { absorption }\end{array}$ \\
\hline & & & 2.547 & 2.532 & 2.522 \\
\hline & Fine aggregate & ASTM (C-128) & 2.644 & 2.618 & 2.602 \\
\hline \multicolumn{2}{|l|}{ Angularity, \% } & $\begin{array}{c}\text { ASTM (D-5821) } \\
\text { Min 90\% }\end{array}$ & \multicolumn{3}{|c|}{$95 \%$} \\
\hline \multicolumn{2}{|l|}{ Soundness } & $\begin{array}{c}\text { ASTM (C-88) } \\
10-20 \%\end{array}$ & \multicolumn{3}{|c|}{$4.8 \%$} \\
\hline $\begin{array}{l}\text { clay content sand } \\
\text { equivalent }\end{array}$ & Fine aggregate & $\begin{array}{c}\text { ASTM (D-2419) } \\
\text { Min } 45 \%\end{array}$ & \multicolumn{3}{|c|}{$94 \%$} \\
\hline \multirow{2}{*}{$\begin{array}{l}\text { Flat and elongated } \\
\text { particles }(\%)\end{array}$} & Flat & \multirow{2}{*}{$\begin{array}{c}\text { ASTM (D-4791) } \\
\text { Max } 10 \%\end{array}$} & \multicolumn{3}{|c|}{$1 \%$} \\
\hline & elongated & & \multicolumn{3}{|c|}{$4 \%$} \\
\hline $\begin{array}{l}\% \text { Loss Angels } \\
\text { Abrasion }\end{array}$ & $\begin{array}{c}\text { Aggregate Size } \\
<25 \mathrm{~mm}\end{array}$ & $\begin{array}{c}\text { ASTM (C-131) } \\
35-45 \%\end{array}$ & \multicolumn{3}{|c|}{$28 \%$} \\
\hline
\end{tabular}

Table (3): Physical properties and standard limitation of asphalt binder

\begin{tabular}{|l|c|c|c|}
\hline Test properties & Standard & Value & SCRB Specification \\
\hline Penetration $(0.1 \mathrm{~mm}, 100 \mathrm{~g}$ and $5 \mathrm{sec})$ & ASTM (D-5) & 45 & $40-50$ \\
\hline Specific gravity & ASTM (D-70) & 1.04 & --- \\
\hline Ductility at $25^{\circ} \mathrm{C}(5 \mathrm{~cm} / \mathrm{min})$ & ASTM (D-113) & 119 & $>100$ \\
\hline Softening point $\left(\right.$ ring and ball) $(4 \pm 1)^{\circ} \mathrm{C} / \mathrm{min},{ }^{\circ} \mathrm{C}$ & ASTM (D-360) & 47 & --- \\
\hline Flash points ${ }^{\circ} \mathrm{C}$ & ASTM (D-92) & 290 & Min.232 \\
\hline Fire points ${ }^{\circ} \mathrm{C}$ & ASTM (D-92) & 310 & --- \\
\hline
\end{tabular}

The molecular structure of SBS can be linear or radial. In linear SBS, two polystyrene (PS) blocks are placed at the ends with poly butadiene (PB), an elastomeric block, in the middle. In radial block copolymer SBS, styrene and butadiene with bound styrene of $32 \%$ mass. contains an astral structure containing more than three blocks of polystyrene. The rigid polystyrene (PS) and polar blocks in SBS make the polymer binder system more resistant to deformation. More polar groups in the 
polymer provide stronger interactions between the asphaltene, More polar groups in the polymer provide stronger interactions between the asphaltene, the polar aromatic components of asphalt and the polymer [7]. Styrene Butadiene Styrene (SBS) Modified Kraton D 1101 produces by Shell Chemical Company is used as a modifier of asphalt or thermoplastics . Properties of used SBS-modifier are solid, white color essentially odorless and with density 880-950 kg/m3. 3\%, 5\% and $8 \%$ of SBS content were used by weight with control asphalt binder. The SBS enhanced asphalt was prepared through using manufactured mixer. The binder was heated to $160{ }^{\circ} \mathrm{C}$ for one hour, after that SBS material was gradually added to the controller asphalt binder 2 hour of mixing time with SBS at $180^{\circ} \mathrm{C}$ (Plate 1), and $2220 \mathrm{rpm}$ shear rate.

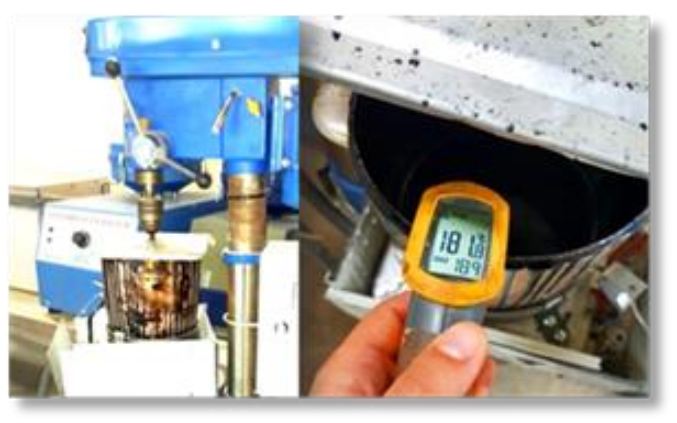

Plate (1): Mixing device and Temperature of blending SBS with asphalt

\section{Results and Discussion}

\subsection{Rutting factor $(G * / \sin \delta)$ for control and} SBS Modified binder

The Superpave parameter $\mathrm{G}^{*} / \sin \delta$ was determined as the firmness pointer for assessing the rutting obstruction of both unmodified and polymer changed folios. Rutting is the dynamic aggregation of changeless misshapening of each layer of the asphalt structure under tedious stacking [10].

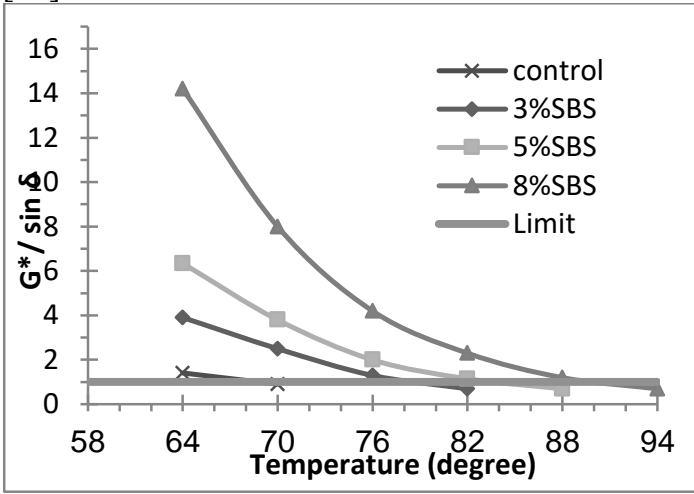

Figure (1): Results rutting factor $\left(\mathrm{G}^{*} / \sin \delta\right)$ for control and SBS Modified binder at different temperatures before RTFOT ageing

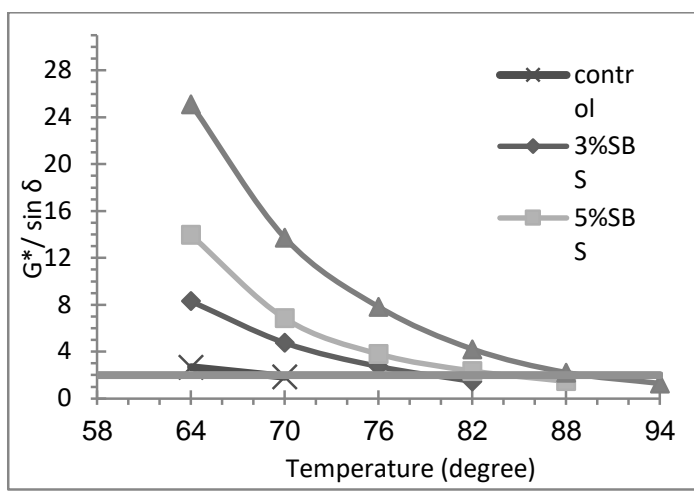

Figure (2): Results rutting factor $\left(\mathrm{G}^{*} / \sin \delta\right)$ for control and SBS Modified binder at different temperatures after RTFOT ageing

The DSR result value displayed that the rutting resistance factor $\left(\mathrm{G}^{*} / \mathrm{sin} \delta\right)$ of SBS Modified asphalt is upper than those of the control asphalt binder at all test temperatures. It is seen from the results that the the rutting resistance factor increased meaningfully with the increase of the SBS modified. The rutting resistance of the binder increases with an increase in the percentage of modifiers. As given in Figure (1), by the addition of 3,5 and $8 \%$ SBS with control asphalt, the rutting resistance is increased by more than $2.8,4.5$ and 10 times at $64^{\circ} \mathrm{C}$.

\subsection{Superpave Property Evaluation}

Superpave property evaluation using DSR was conducted for the Neat asphalt, 3\%, 5\% and $8 \%$ SBS respectively. Figure, (3) shows the testing results for both neat and RTFO asphalt, at high temperatures. According to Figure, (3), the performance grade (PG) for the control asphalt 3, 5 and $8 \%$ SBS are finalized as PG 64-16, PG 7616, PG 82-16, PG 88-16 respectively. This proves that all of the three modifiers can significantly improve the properties of control asphalt.

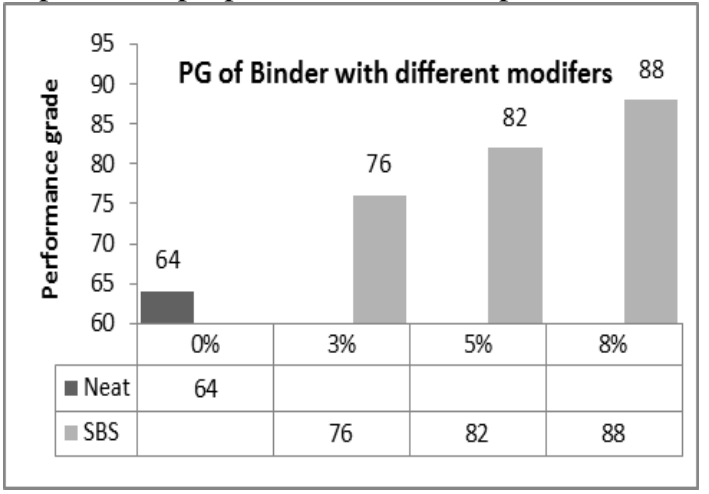

Figure (3): PG of High temperature of Binder with Different Modifiers

\subsection{Finding Viscosity of Modified Asphalt Binders}

For this research, three binders were found PG 76 (3\% SBS modified), PG 82 (5\% SBS modified) and PG 88 (8\% SBS modified). Everything about 
Modified Asphalt was tried utilizing the Rotational viscometer, which used shear rates $(3.4,6.8,10.2$, 17, 20.4 and $34 \mathrm{~s}^{-1}$ ) with RPM from (10 to 100) using spindle numbers 27 . Three viscosity measurements were collect at $135^{\circ} \mathrm{C}$ and $165^{\circ} \mathrm{C}$, then the average of these values were plotted on a graph of viscosity versus shear rate. Figures (3, 4, 5) show viscosity versus shear rate and the corresponding equations that were used to calculate viscosities at shear rates of $\left(500 \mathrm{~s}^{-1}\right)$ for $135^{\circ} \mathrm{C}$ and $165^{\circ} \mathrm{C}$. Since this chart is extrapolated to a shear rate of $\left(500 \mathrm{~s}^{-1}\right)$, it is important to calculate the viscosity at this rate. Using the equation from the power fit of the trend line to the viscosity versus shear rate data. Rotational viscosities for modified Binder at different percentage at $135^{\circ} \mathrm{C}$ are shown in Table (4). The results show an increase in viscosity with polymer modification for all modified Binder . In addition, rotational viscosities $(\eta)$ at $135{ }^{\circ} \mathrm{C}$ for the control Asphalt and modified Binder are presented in Table (4) together with modification indices $(\eta$ for modified Binder divided by $\eta$ for the control Asphalt) at 135 temperatures for Superpave method and High Shear Rate Viscosity original method. The viscosities give a reasonable sign of the solidifying impact of alteration. It was determined that SBS modified reached a viscosity of 3 (Pa.s) at 8 additive, so additive contents above these values may not be suitable for good workability and pump ability according to Superpave specifications. As given in table 3 shows that viscosity increased by 3.7 and 3.14 times as adding $5 \% \mathrm{SBS}$ at $135{ }^{\circ} \mathrm{C}$ according to superpave and high shear rate methods respectively.

Table (4): Viscosity at $135^{\circ} \mathrm{C}$ for different

Modified asphalt

\begin{tabular}{|l|c|c|c|c|}
\hline \multirow{2}{*}{ Binder } & \multicolumn{2}{|c|}{$\begin{array}{c}\text { Superpave } \\
\text { method }\end{array}$} & \multicolumn{2}{c|}{ HSRV-O } \\
\cline { 2 - 5 } & $\begin{array}{c}\eta \\
\text { modified } \\
\text { (Pa.s) }\end{array}$ & $\begin{array}{c}\eta \text { modified/ } \\
\eta \text { control }\end{array}$ & $\begin{array}{c}\eta \\
\text { modified } \\
\text { (Pa.s) }\end{array}$ & $\begin{array}{c}\eta \text { modified/ } \\
\eta \text { Asphalt }\end{array}$ \\
\hline Control & 0.538 & 1.00 & 0.538 & 1.00 \\
\hline $3 \%$ SBS & 1.462 & 2.72 & 1.217 & 2.26 \\
\hline $5 \%$ SBS & 1.996 & 3.71 & 1.687 & 3.14 \\
\hline $8 \%$ SBS & 2.829 & 5.26 & 2.333 & 4.34 \\
\hline
\end{tabular}

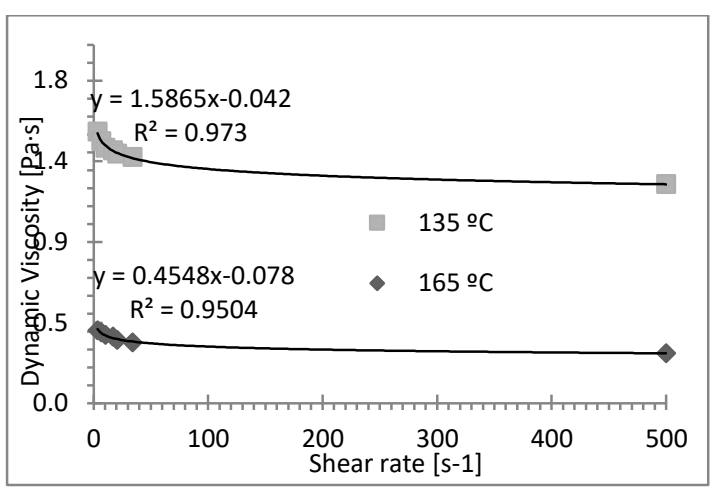

Figure (4): Viscosity Vs. Shear rate at $135^{\circ} \mathrm{C}$ and $165{ }^{\circ} \mathrm{C}$ for $3 \%$ SBS Modified binder

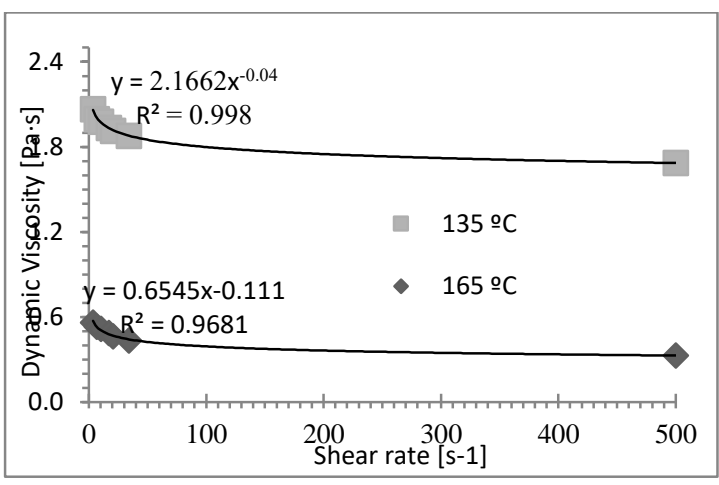

Figure (5): Viscosity Vs. Shear rate at $135^{\circ} \mathrm{C}$ and $165{ }^{\circ} \mathrm{C}$ for $5 \%$ SBS Modified binder

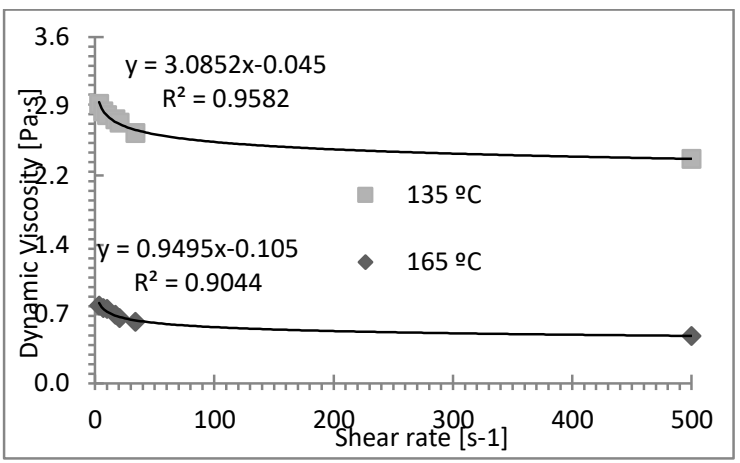

Figure (6): Viscosity Vs. Shear rate at $135{ }^{\circ} \mathrm{C}$ and $165{ }^{\circ} \mathrm{C}$ for $8 \%$ SBS Modified binder

\subsection{Optimum Asphalt Content (OAC)}

Marshall mix design (ASTM D6927) with the aim of determining the optimum asphalt content in HMA pavement for control and modified asphalt binder mixtures by using Marshall Test method. Five different percentage values were used for asphalt cement $(4,4.5,5,5.5$ and 6$)$ percent were used. Two identical samples were produced for each asphalt ratio. Therefore, 10 specimens were preparing for the OAC determination. Properties of The mixtures at optimum contents of asphalt should be discussed with requirements of the Iraqi specification for the pavement binder layer. It was found that $\mathrm{OAC}$ required was (4.9\%) for conventional and modified asphalt mixtures. 


\subsection{Effect of Compaction Temperature and Modified Content on Marshall Properties}

Marshall Properties at four Compaction temperature of $120,140,160$ and $180{ }^{\circ} \mathrm{C}$, for each of the three modifiers (3, 5 and 8 ) \% SBS have been found. The effects of the compaction temperature were evaluated for the following Marshall results from the Hot Mix Asphalt. Figure (7) shows relation of Marshall Stability and compaction temperature. it can be notice the compaction temperature from (120 to $\left.160{ }^{\circ} \mathrm{C}\right)$ stability values slightly increases, gradually increases and sharply increases at (3, 5 and $8 \% \mathrm{SBS}$ ) respectively. The compaction temperature from $\left(160\right.$ to $\left.180{ }^{\circ} \mathrm{C}\right)$ the stability values gradually decreases, slightly decrease and steadily increases in $(3,5,8 \%$ SBS) respectively. Wherever the amount of Marshal stability of compaction temperature $\left(160{ }^{\circ} \mathrm{C}\right)$ is around $14 \%$ higher, $5 \%$ higher and $6 \%$ lower than if compacted at $\left(180{ }^{\circ} \mathrm{C}\right)$, and $5 \%, 11 \%$ and 26 higher if compacted at $\left(140^{\circ} \mathrm{C}\right)$ despite the fact it upsurges to $27 \%, 44 \%, 51 \%$ if compacted at $\left(120^{\circ} \mathrm{C}\right)$. The addition of $(3,5$ and $8 \%$ SBS $)$ increases the strength of the SBS specimens as compared to the conventional specimens an increase of about 39,74 and $102 \%$.

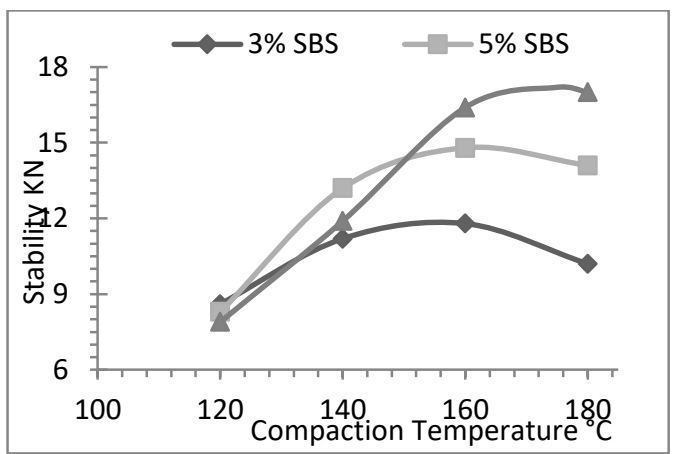

Figure (7): Effect of compaction Temperature and SBS modified on Marshall Stability

Air voids content is one of the critical parameters of the binder blend, which is for the most part in the vicinity of $3 \%$ and $5 \%$ in Iraq, which should meet the particular SCRB. With a specific end goal to ensure the porousness, the base air voids content in this examination is set at $3.5 \%$. The standard Marshall examples are made by the analysis plan prerequisite determination. Porosities of the examples created at various compaction temperatures and and modified content. Figure (8) shows the relationship between different compaction temperatures in $\left({ }^{\circ} \mathrm{C}\right)$ versus percentage VTM. It is found that as the compaction temperature up from $140{ }^{\circ} \mathrm{C}$ to $180{ }^{\circ} \mathrm{C}$, VTM sharply decrease. The value of VTM was $5.1,5.4$ and $6.1 \%$ in 3,5 and $8 \%$ SBS at $120^{\circ} \mathrm{C}$ and reduced to $3.9,4.1$ and $4.2 \%$ at $160{ }^{\circ} \mathrm{C}$, While these values decrease slightly as the compaction temperature increases than $160^{\circ} \mathrm{C}$, its value is $3.6,3.5$ and $3.8 \%$ at $180{ }^{\circ} \mathrm{C}$.

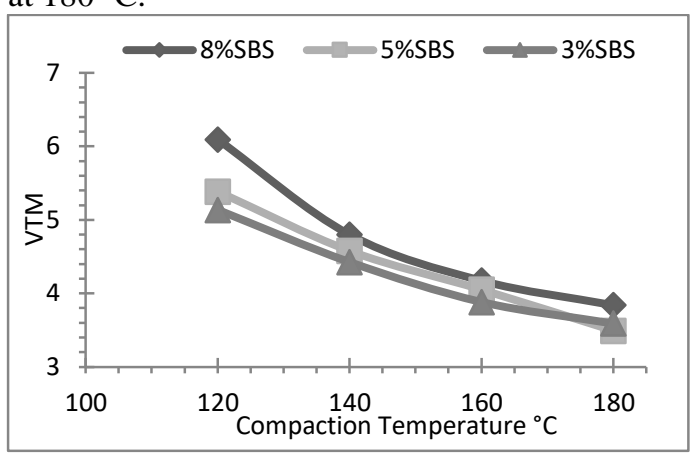

Figure (8): Effect of compaction Temperature and SBS modified on Air voids

\subsection{Effect of Compaction Temperature and modified content on Bulk Density}

Figure (9) show increasing of bulk density with increase compaction temperature For mixture SBS modified, it is found that when the compaction temperature decreases from 180 to $140{ }^{\circ} \mathrm{C}$ for $3 \%$ SBS and 180 to $160{ }^{\circ} \mathrm{C}$ for 5 and $8 \%$ SBS the density values remain constant. This reproduces that the binder mix is an additional practical owing to the low viscosity of asphalt that greased aggregate element fine at that variety of temperatures. At the compaction temperature from 160 to $140{ }^{\circ} \mathrm{C}$ for 5 and $8 \%$, SBS The density values decrease since asphalt viscosity may upsurge suddenly which reason a sharp reduction in bulk density with the similar tendency at the compaction temperature decreases from (140 to $120^{\circ} \mathrm{C}$ ), for 3,5 and $8 \%$ SBS. , the asphalt becomes very stiff and compaction becomes tremendously problematic, so the bulk density is lessening in this region when the compaction temperature cool off down

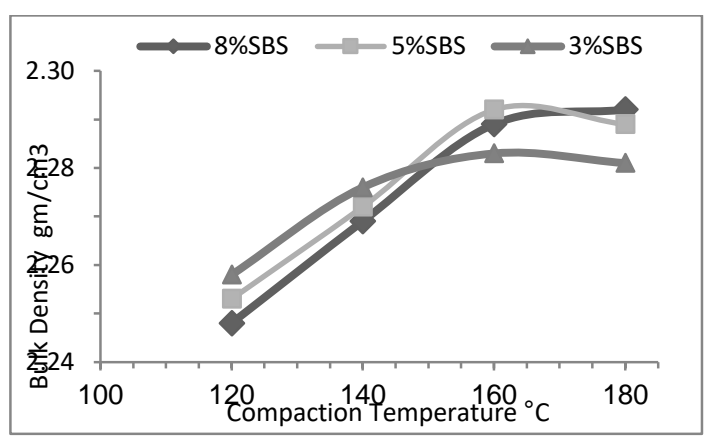

Figure (9) Effect of compaction temperature and SBS modified on Bulk Density

\subsection{Determination of optimum compaction temperature from Marshall Test}

The optimum compaction temperature of hot mix asphalt is determined by taking the average values of three-compaction temperature resultant 
to max. stability, max. bulk specific gravity and $4 \%$ Air Voids. The optimum compaction temperature for mix is the average of three values shown in Table (5).

Table (5) Optimum compaction temperatures from Marshall Test

\begin{tabular}{|c|c|c|c|c|}
\hline \multirow{3}{*}{ Binder } & \multicolumn{3}{|c|}{$\begin{array}{c}\text { Compaction Temperature }\left({ }^{\circ} \mathrm{C}\right) \\
\text { Corresponding To }\end{array}$} & $\begin{array}{c}\text { OCT } \\
\text { From } \\
\end{array}$ \\
\cline { 2 - 4 } & Max. & $\begin{array}{c}\text { Max. } \\
\text { Gmb }\end{array}$ & $\begin{array}{c}\text { 4\%Air } \\
\text { Voids }\end{array}$ & $\begin{array}{c}\text { Mall } \\
\text { Test }\end{array}$ \\
\hline $3 \%$ SBS & 155 & 155 & 160 & 157 \\
\hline $5 \%$ SBS & 165 & 163 & 165 & 164 \\
\hline $8 \%$ SBS & 175 & 170 & 180 & 175 \\
\hline
\end{tabular}

\subsection{Comparison between Superpave, HSRV and Marshall Methods}

For the control asphalt, the Mixing temperatures are lower than $163^{\circ} \mathrm{C}$ and above $158^{\circ} \mathrm{C}$. Compaction temperatures are lower than $152^{\circ} \mathrm{C}$, and above $147^{\circ} \mathrm{C}$. The Superpave method provides rational results when applied to paving grades asphalt The temperatures obtained from Superpave method for the modified asphalt are illustrated in Figures (10) and (11). It is observed that mixing, compaction temperatures increase proportional to the modified content, that, in general terms, are higher than optimum compaction temperature by Marshall Test mixing and compaction temperatures are very high, above $180^{\circ} \mathrm{C}$, which can cause degradation of binder and has environmental and health risks. As expected, this method is considered unsatisfactory. Figure 49 and 50 illustrate the variation of the maximum and the minimum temperatures with used determination by each method.

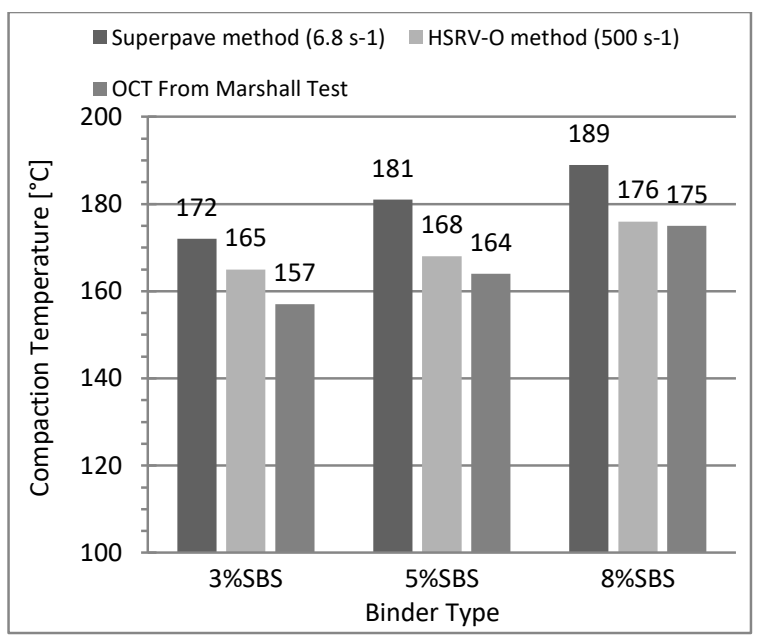

Figure (10) Compaction temperatures determined by the following Methods: a) Superpave; b)

HSRV; c) OCT from Marshall Test

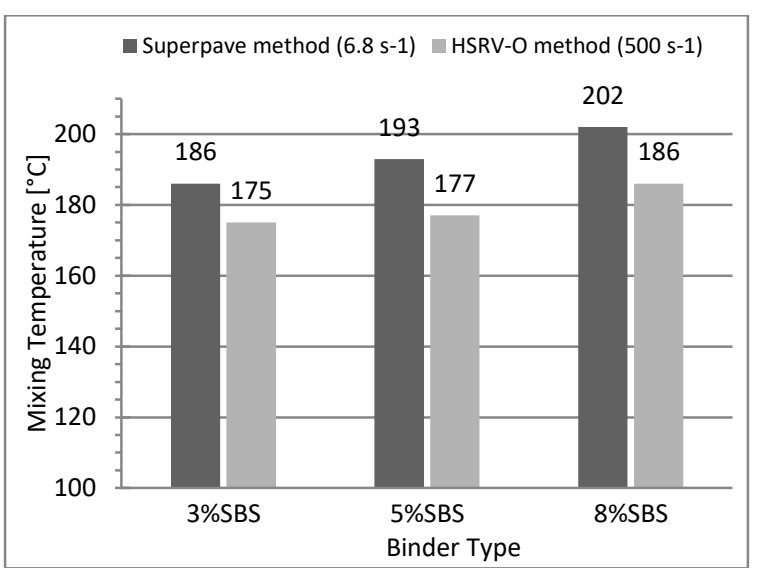

Figure (11) Mixing temperatures determined with the following methods: a) Superpave; b) HSRV-O

\section{Conclusion}

1. The results showed that the addition of $3 \%$ SBS modified prepared with control binder had the performance level PG 76-16 while adding about $5 \%$ SBS can increase the PG grade of the binder by at least three grades (from PG 64-16 to PG 82-16). The addition of $8 \%$ SBS can increase the PG grade of the binder by at least four grades (from PG 6416 to PG 88-16)

2. It is noted that SBS modified reached a viscosity of 3 Pa.s when $8 \%$ additive. Additive contents above these values may not be suitable for good workability and pump ability according to Superpave specifications. While addition of $5 \%$ SBS with control asphalt, more than 3.7times at $135^{\circ} \mathrm{C}$ Increase the viscosity. Increase less if used High Shear Rate Viscosity original method in 3.14 at the same temperature.

3. Marshall Stability test indicated that the strength for the SBS specimens increases as compared to the conventional specimens. An increase of about 39\%, 74\%, 102\%, was observed with 3\%SBS 5\%SBS $8 \%$ SBS modified binders, respectively.

4. The Marshall Test results showed to $8 \%$ SBS binders required compaction temperatures above $175^{\circ} \mathrm{C}$ given the ever-display need to keep up HMA item quality while limiting natural effect amid development, these proposals are unsatisfactory Modified mixtures the 5\% SBS modification was determined to be the maximum useful content.

5. The Superpave method to estimate mixing and compaction temperatures show are not practical for use with modified binders. As seen in the results all binders required a mixing temperature above $165^{\circ} \mathrm{C}$. Observes that $3 \%$ SBS, $5 \%$ SBS, $8 \%$ SBS, binders required compaction temperatures above $180^{\circ} \mathrm{C}$, and $8 \% \mathrm{SBS}$ required mixing temperatures of $200^{\circ} \mathrm{C}$. In the heated binders excessively, binder oxidizes at such a high rate, to the point that solidifying can cause critical harm. Some modifiers are themselves warm, delicate and may 
separate amid inappropriate utilize. At long last, one must consider generation costs, which may increment because of exorbitant vitality utilize and safety measures expected to secure specialists and adjacent inhabitants.

6. The optimum compaction temperature (OCT) by Marshall Test determines average compaction temperatures Almost identical to The HSRV-O method and lower than Superpave methods Where the decline ranges from $15^{\circ} \mathrm{C}$ to $17^{\circ} \mathrm{C}$

7. The HSRV-O method determines the lower average mixing and compaction temperatures than Superpave methods. The proposed approach shows that the blending temperature will be around $11^{\circ} \mathrm{C}$ (3\% SBS) to $16^{\circ} \mathrm{C}(8 \%$ SBS $)$ bring down when the shear rate is considered. For compaction temperature, a decrease of around $7{ }^{\circ} \mathrm{C}(3 \%$ SBS $)$ to $13{ }^{\circ} \mathrm{C}(8 \%$ SBS $){ }^{\circ} \mathrm{C}$ is observed.

\section{References}

[1] Airey, Rheological properties of styrene butadiene styrene polymer modified road bitumens. Fuel, 82.14 : 1709-1719.( 2003)

[2] Albayati H. Amjad and Al-Azawee T. Esraa, Properties of Epoxy-Asphalt Pavement Mixture for Bridge Decks, Al-Nahrain Journal for Engineering Sciences (NJES) Vol.21 No.1, 2018 pp.20-27

[3] ASTM D2493 / D2493M-16, Standard Practice for Viscosity-Temperature Chart for Asphalt Binders, ASTM International, West Conshohocken, PA, (2016)
[4] ASTM D4402 / D4402M-15, Standard Test Method for Viscosity Determination of Asphalt at Elevated Temperatures Using a Rotational Viscometer, ASTM International, West Conshohocken, PA, (2015)

[5] ASTM D6927-15, Standard Test Method for Marshall Stability and Flow of Asphalt Mixtures, ASTM International, West Conshohocken, PA, (2015)

[6] ASTM D7175-15, Standard Test Method for Determining the Rheological Properties of Asphalt Binder Using a Dynamic Shear Rheometer, ASTM International, West Conshohocken, PA, (2015)

[7] Becker, et al. Polymer modified asphalt. In: Vision tecnologica. 9. 1, (2001)

[8] SCRB/R9, General Specification for Roads and Bridges, Section R/9, Hot-Mix Asphalt Concrete Pavement, Revised Edition. State Corporation of Roads and Bridges, Ministry of Housing and Construction, Republic of Iraq (2003)

[9] WEST, Randy C., et al. Mixing and compaction temperatures of asphalt binders in hot-mix asphalt. (2010)

[10] WONG, W. G., et al. Rutting response of hotmix asphalt to generalized dynamic shear moduli of asphalt binder. Construction and Building Materials, 18.6: 399-408.(2004)

[11] Yildirim, et al. Evaluation of viscosity values for mixing and compaction temperatures. Journal of materials in civil engineering, 18.4: 545-553.(2006).

\section{تقييم درجات الحرارة خلط ودمك الأسفلت المعدل باستخدام طريقتي السوبربيف

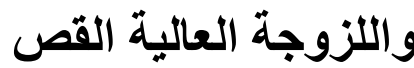
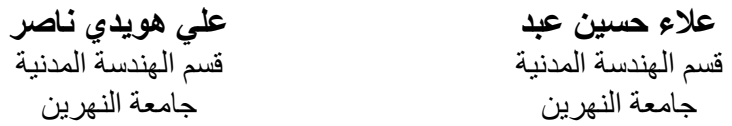

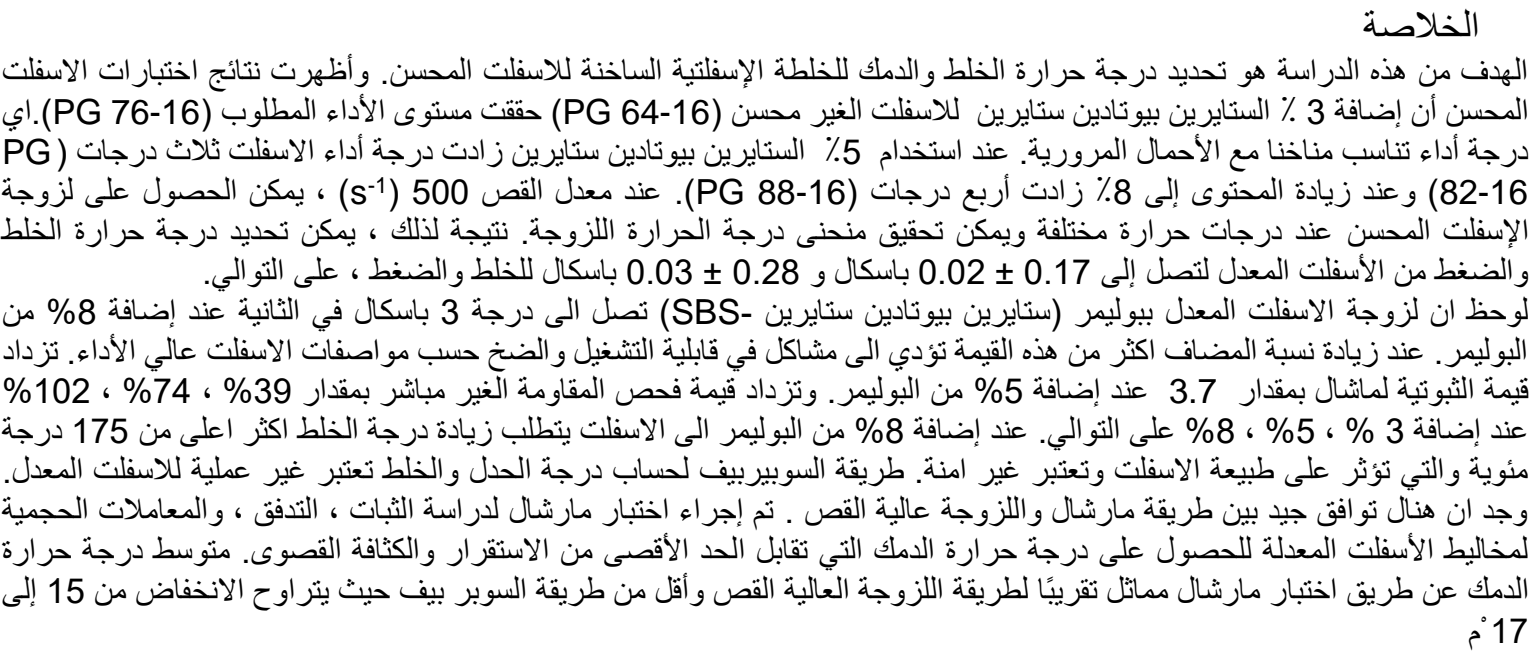

